\title{
Quantitative separation of bacteria in saline solution using lanthanide Er(III) and a magnetic field
}

\author{
Maciej Zborowski, ${ }^{1 *}$ Paul S. Malchesky, ${ }^{1}$ Tyan-Fu JaN ${ }^{1}$ and Geraldine S. Hall ${ }^{2}$ \\ ${ }^{1}$ Department of Biomedical Engineering and Applied Therapeutics, and ${ }^{2}$ Department of Microbiology, The Cleveland \\ Clinic Foundation, One Clinic Centre, 9500 Euclid Avenue, Cleveland, Ohio 44195-5254, USA
}

(Received 18 March 1991; revised 9 July 1991; accepted 12 September 1991)

\begin{abstract}
A trivalent lanthanide ion, erbium $\left(\mathrm{Er}^{3+}\right)$, has been used in combination with a magnetic separation technique to isolate seven bacterial species from suspensions in $0.9 \%$ saline. Erbium has an exceptionally high atomic magnetic moment of 9.3 Bohr magnetons, and following addition as $\mathrm{ErCl}_{3}$ (final concentration $5 \mathrm{mM}$ ) to bacterial suspensions, it imparts the magnetic moment to the bacterial cells by ionic binding to the cell surface. Strains of Escherichia coli, Klebsiella pneumoniae, Proteus mirabilis, Psuedomonas aeruginosa, Staphylococcus epidermidis, Staphylococcus saprophyticus and Enterococcus faecalis were obtained from the Quality Control Depository of The Cleveland Clinic Foundation, Cleveland, Ohio, USA as suspensions in $0.9 \% \mathrm{NaCl}$, in concentrations ranging from $10^{2}$ to $10^{8} \mathrm{c.f}$.u. $\mathrm{ml}^{-1}$. Bacteria were separated from solution inside a capillary flow cell exposed to a highly non-homogeneous magnetic field (maximum field intensity was $0.4 \mathrm{~T}$ ) and quantified by a light scattering method. The quantity of cellular deposition in the magnetic field was correlated with the initial concentration of cells in the suspension, expressed in c.f.u. $\mathrm{ml}^{-1}$, and sample volume (1.5 and $3.0 \mathrm{ml}$ ), sample $\mathrm{pH}$ (prior to $\mathrm{ErCl}_{3}$ addition), affinity to Gram stain (negative vs positive) and species. Magnetic deposition was observed for concentrations as low as $10^{2}$ and $10^{3} \mathrm{c.f}$.u. $\mathrm{ml}^{-1}$, and a significant correlation between average scattered light intensity and initial cell concentration (correlation coefficient $\geq 0.98$ ) was established in the range $10^{4}$ to $10^{8}$ c.f.u. $\mathrm{ml}^{-1}$ for all but one species ( $P$. aeruginosa). Magnetic deposition increased with increasing $\mathrm{pH}$ from 7.0 to 10.0 which is consistent with the prevailing view on the mechanism of the lanthanide ion binding to bacterial cells (ionic, to the cell surface). No significant difference in magnetic deposition was observed between individual strains, or between Gram-positive and -negative bacteria. Magnetic isolation of cells may find application in rapid total cell count determination, such as rapid urine screening.
\end{abstract}

\section{Introduction}

At the present time there are several commercial sources of magnetic reagents suitable for use in the magnetic separation of cells. The reagent which has become most widely reported, as used in the laboratory as well as the clinical purification of cells, is a suspension of uniformlysized polymeric beads doped with magnetite and surfacecovered with different functional groups, such as - $\mathrm{COOH}$ (Bangs Laboratories) suitable for binding to target cells.

Beads conjugated to a selection of antibodies, such as sheep anti-mouse IgG (Dynabeads, Dynal) (Kemshead et al., 1990) or anti-human leukocyte (Collaborative Research) are also available. The available sizes of the beads range from submicron to $\mathrm{mm}$.

In this study we have used $\mathrm{ErCl}_{3}$ which forms trivalent erbium cations in aqueous solution and preserves its exceptionally high atomic magnetic dipole moment $(9 \cdot 3$ Bohr magnetons) in various chemical structures (Bozorth, 1968). The published data demonstrate that lanthanides, such as $\mathrm{Er}$, have a high affinity for the external cell surface of micro-organisms (Evans, 1990). In previous studies by other authors, erbium, dysprosium, holmium, thulium, and gadolinium were evaluated for efficacy in imparting magnetic susceptibility to polymeric particles and their subsequent removal from flowing fluid by a non-homogeneous magnetic field (Ahlberg \& Walley, 1982; Evans \& Tew, 1983; Russell et $a l ., 1987)$. Erbium was used for magnetization of osseus and cartilaginous wear particles in specimens of synovial fluid followed by magnetic separation and morphological analysis (Evans, 1983). Preliminary results on magnetic separation of erbium-treated bacteria and blood cells have also been reported (Russell et al., 1983; Zborowski et al., 1991). 


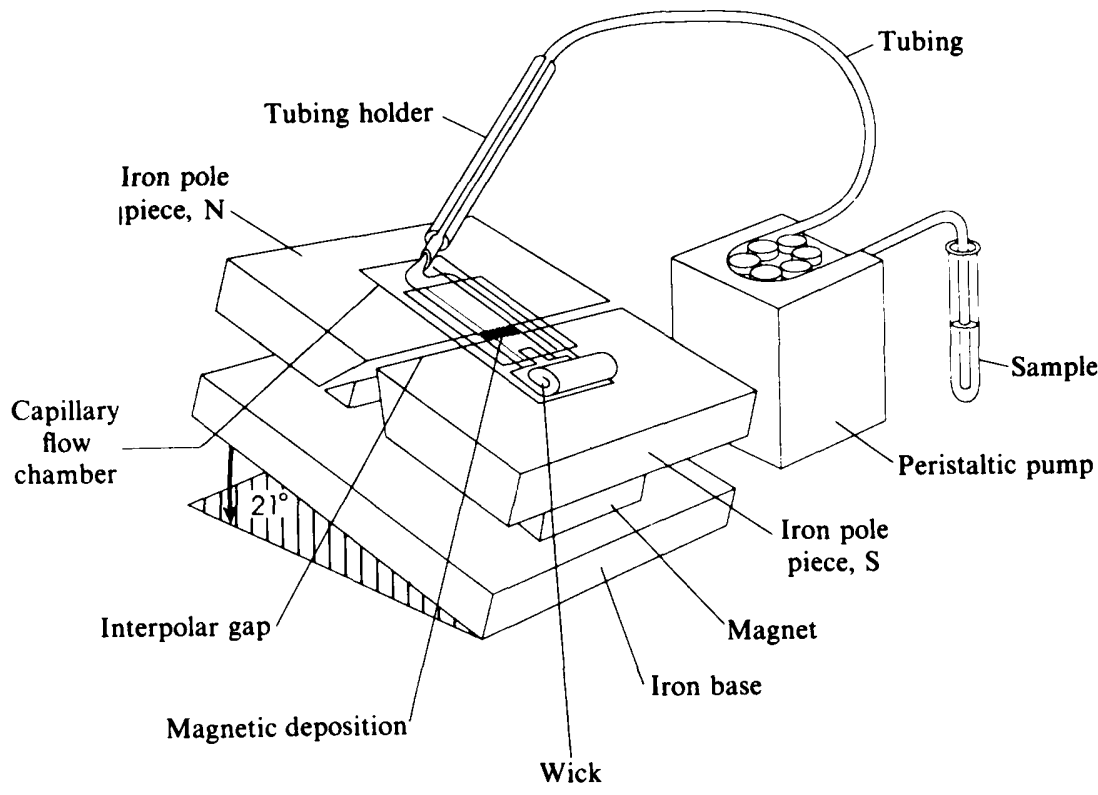

Fig. 1. Elements of the magnetic separation process. A sample of bacterial suspension with $5 \mathrm{mM}-\mathrm{ErCl}_{3}$ was transferred by a peristaltic pump to a capillary flow glass chamber where the magnetized cells separate from the flowing medium and concentrate at the bottom of the flow chamber in the area of the interpolar gap of a strong permanent magnet assembly. The effluent is absorbed by a wick mounted at the fluid exit end of the flow chamber whereby the magnetically concentrated cells are dry-fixed inside the chamber. Following the magnetic concentration, the wick with the absorbed fluid is discarded and the flow chamber with the concentrated cells is transferred to a microscope (not shown) set in a dark background mode and coupled to a light detector meter and recorder. The scattered light intensity, proportional to the number of cells in the microscope field of view, is recorded as a function of distance along the flow chamber's longitudinal axis of symmetry.
The magnetic separation technique and the evaluation of the magnetically concentrated cellular mass was adapted from an industrial instrument, the ferrograph, used for screening of wear particles in engine lubricants (Anderson, 1983). The particular questions posed in this study were: (1) is magnetic separation of bacteria capable of producing a quantitative measure of the cell concentration in the sample, (2) what is the sensitivity of the method for evaluating cell concentration in $0.9 \%$ saline suspensions of typical bacterial species found in urine and (3) are there any differences in the separation of Gram-positive and -negative species? The results of this study were compared with the results of bacterial growth and colony counts on solid media.

\section{Methods}

Bacterial suspensions. All seven species of bacteria which were used in this study, Escherichia coli, Klebsiella pneumoniae, Proteus mirabilis, Pseudomonas aeruginosa, Staphylococcus epidermidis, Staphylococcus saprophyticus, and Enterococcus faecalis, were obtained as suspensions in $0.9 \%$ saline from the Quality Control strains (stored at $-20{ }^{\circ} \mathrm{C}$ ) of the Microbiology Department of the Cleveland Clinic Foundation, Cleveland, Ohio, USA. These bacterial suspensions were diluted to about $1.0 \times 10^{8}$ c.f.u. ml ${ }^{-1}$ as evaluated by McFarland standards of $\mathrm{BaCl}_{2}$ (aq) turbidity in filtered normal saline $(0.9 \% \mathrm{NaCl}, 0.2 \mu \mathrm{m}$ sterile filter, Gelman Sciences). The original bacterial suspensions, whose $\mathrm{pH}$ values were between 6.5 and 7.0 , were then sequentially diluted tenfold with filtered normal saline and adjusted to a specified $\mathrm{pH}$ value of $4 \cdot 0$, $6 \cdot 0,7 \cdot 0,8 \cdot 0,9 \cdot 0$ or 10.0 using $0.5 \mathrm{~mm}-\mathrm{NaOH}$ or $\mathrm{HCl}$ solutions previously filtered with $0.2 \mu \mathrm{m}$ filters. The concentration of the bacterial suspensions was also evaluated by colony counting after $24 \mathrm{~h}$ incubation at $35^{\circ} \mathrm{C}$.

Magnetizing agent. $\mathrm{ErCl}_{3}$ ( $99.99 \%$ purity, A. Johnson Matthey) was prepared in ready-to-use vials. This was done by dissolving solid $\mathrm{ErCl}_{3}$ in twice-distilled water to give a stock solution with a concentration of $150 \mathrm{~mm}$. The stock solution was filtered through a $0.2 \mu \mathrm{m}$ filter and dispensed in $50 \mu \mathrm{l}$ volumes to each sample vial ( $1.5 \mathrm{ml}$, Tekmar Co.). The vials were placed in a convective heating cabinet at $60^{\circ} \mathrm{C}$ for $6 \mathrm{~h}$ to evaporate off the water. The concentration of $\mathrm{ErCl}_{3}$ in the vials was 5 $\mathrm{mM}$ after addition of $1.5 \mathrm{ml}$ bacterial suspension.

Bacterial deposition substrate. The bacterial deposition substrate consisted of two sections. One section was the flow chamber made from modified microscope cover slides, and the other section was a wick made from filter paper, as illustrated in Fig. 1. The wick served the purpose of collecting the effluent from the flow chamber. The flow chamber was made of two glass slides, $60 \mathrm{~mm}$ long $\times 25 \mathrm{~mm}$ wide $\times 0.2$ $\mathrm{mm}$ thick, with a painted Teflon pattern forming a $5 \mathrm{~mm}$ wide fluid channel. These slides were provided by the Standard Oil Engineered Materials Co. and were prepared for use in their Slide Ferrograph Analyzer (Zborowski et al., 1991). Three layers of Scotch double-coated tape (\#665, 3M Co.) separated the bottom slide from top slide by $0.2 \mathrm{~mm}$.

Magnet assembly. A pair of neodymium-iron-boron magnets (maximum energy product 28 MGOe, dimensions $5 \times 5 \times 1.3 \mathrm{~cm}$; Permag Co.) were used. The magnets were connected by a large bottom plate and two pole pieces of soft iron with tapered ends for amplification of magnetic flux lines in the area of the interpolar gap in which the magnetic separation took place. An aluminium plate of 1.4 mm thickness maintained a uniform distance between the pole pieces of the magnet and formed a high field-intensity, high field-gradient magnetic separation area (Fig. 1).

Experimental procedure. The investigational plan consisted of optimization of the magnetic separation parameters at low concentrations of a single bacterial species in saline suspensions, and determination of differences in magnetic separation between Gramnegative vs Gram-positive species mixtures.

Bacterial suspensions with preset concentrations of $10^{2}, 10^{3}, 10^{4}$, $10^{5}, 10^{6}$ or $10^{8}$ c.f.u. $\mathrm{ml}^{-1}$ at volumes of $3.0 \mathrm{ml}$ were added to the $\mathrm{ErCl}_{3}$ vials and incubated at $37^{\circ} \mathrm{C}$ for $3 \mathrm{~min}$. The solutions were then pumped through Tygon tubing (i.d. $\frac{1}{16}$ in, o.d. $t$ in. length $1.5 \mathrm{ft}$; Fisher Scientific Co.) into the separation chamber placed onto the magnet at a flow rate of $1 \mathrm{ml} \mathrm{min}^{-1}$ using a peristaltic pump (Perista, Atto). After pumping 
the sample, the flow channel was dried using the Microduster (Texwipe) to dry the specimen.

The solid deposition of bacterial cell mass in the interpolar gap region of the separation chamber was quantified by measurement of the intensity of light scattered by the deposition using a photographic exposure meter attached to a microscope (BH-2, Olympus). The microscope was adjusted for dark background viewing. The intensity of light scattered by the individual bacterial cells present in the flow chamber was recorded as a function of position of the microscope stage using an $x-y$ recorder (Plotamatic type 815M, MFE Corporation). The $y$ input was connected to the exposure meter and the $x$ input was connected to a 10-revolution potentiometer linked to a longitudinal stage position knob supplied with $12 \mathrm{~V} \mathrm{DC}$. The area under the plotted peak of the scattered light intensity as a function of distance $y$ vs $x$, within the range of twice the width of the interpolar gap and centred about the midline of the gap, was measured with a planimeter (Keuffel $\&$ Esser Co.). The value obtained is referred to as an average scattered light intensity $I_{\mathrm{av}}$, in relative units.

The values of $I_{\mathrm{av}}$ were correlated with the values of initial bacterial concentrations, $c$, and the $\mathrm{pH}$ values of the initial bacterial suspension.

The interference due to dust particles and other possible artefacts ('noise') were evaluated using $0.9 \%$ saline in $3.0 \mathrm{ml}$ vials with $\mathrm{ErCl}_{3}$ and processed in the same way as the bacterial samples.

The results were analysed by Statgraphics (Version 2.6, STSC) on an IBM AT personal computer using regression analysis (correlation coefficient, intercept, slope, line of $95 \%$ confidence limit) and hypothesis testing by Student's $t$ test (a difference was taken as significant if $P<0.05$ ).

\section{Results}

The optimization of magnetic separation parameters was done using $E$. coli. The magnetic separator response to two different volumes of the sample, 1.5 and $3 \mathrm{ml}$, of $10^{5}$ c.f.u. E. coli $\mathrm{ml}^{-1}$ is presented in Fig. 2. The number of magnetically collected cells rose in direct proportion to the volume of the sample.

The effects of $\mathrm{pH}$ on the number of magnetically collected cells, as measured by the light scattering technique, is presented in Fig. 3 showing data obtained for E. coli, P. aeruginosa and Ent. faecalis. These studies were performed with cell concentrations adjusted to $10^{5}$ c.f.u. $\mathrm{ml}^{-1}$. A significant correlation between $\mathrm{pH}$ and the strength of the scattered light signal was observed in the range $\mathrm{pH} 7.0$ to 10.0 for all three species. The correlation was weak, but still noticeable, in the range $\mathrm{pH} \mathrm{4.0} \mathrm{to} \mathrm{7.0.}$ In the protocol used for subsequent evaluation of the sensitivity of the magnetic separation technique the samples were adjusted to $\mathrm{pH} 8.6$ prior to mixing with $\mathrm{ErCl}_{3}$.

Fig. 4 shows the correlation between the number of magnetically collected cells, as measured by the scattered light intensity, $I_{\mathrm{av}}$, and their initial concentration, $c$, as evaluated by colony counting, for all seven species. Control samples, comprising only $0.9 \% \mathrm{NaCl}$ and $5 \mathrm{~mm}$ $\mathrm{ErCl}_{3}$, showed $\ln I_{\mathrm{av}}<0$. The correlation coefficient of a regression line between mean $\ln I_{\mathrm{av}}$ and $\log c$ was equal to or higher than 0.98 for concentrations ranging from

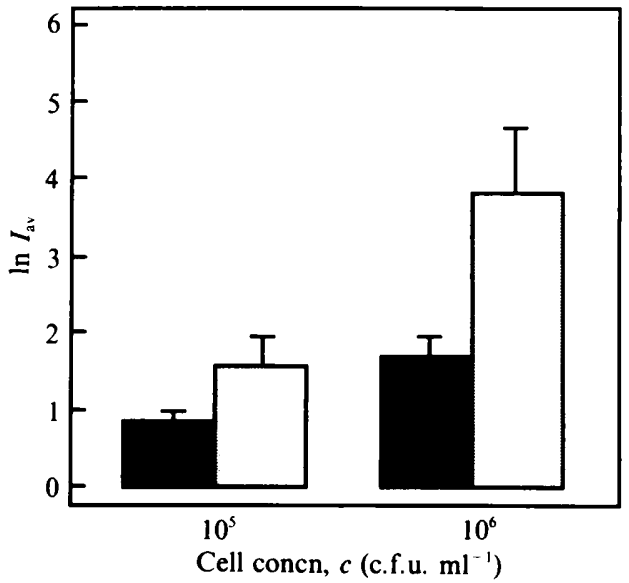

Fig. 2. Variation of cellular deposition density in the magnetic field, quantified by scattered light measurements, with $1.5(\square)$ or $3.0 \mathrm{ml}(\Gamma)$ sample pumped through the flow chamber (at constant cell concentration) and with varying cell concentration (at constant sample volume). Cell type: $E$. coli incubated for $3 \mathrm{~min}$ with $5 \mathrm{mM}-\mathrm{ErCl}_{3}$ in physiological saline at $37^{\circ} \mathrm{C}$; initial $\mathrm{pH}$ of cell suspension, $6 \cdot 0$.

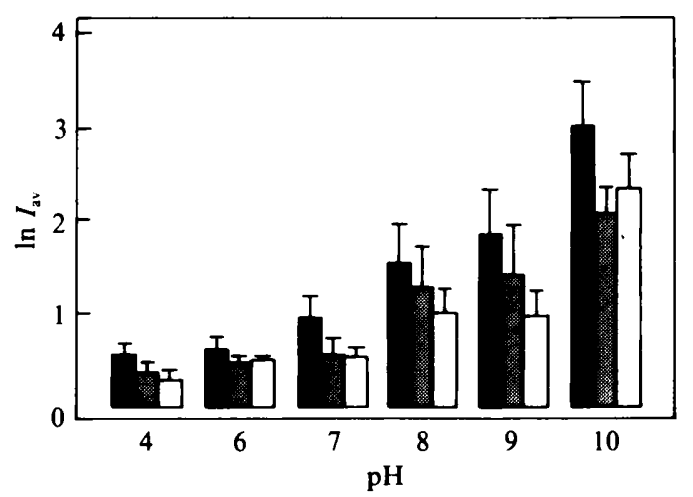

Fig. 3. Variation of cellular deposition density in the magnetic field, quantified by scattered light measurements, with varying initial $\mathrm{pH}$ of the cell suspension prior to incubation with $5 \mathrm{mM}-\mathrm{ErCl}_{3}$ (sample volume $3 \mathrm{ml}$ ). Bacteria : $E$. coli $(\square), P$. aeruginosa (可) and Ent. faecalis ( $\square$ ).

$3 \leq \log c \leq 8$ for four of the seven species, Prot. mirabilis, S. epidermidis, S. saprophyticus and Ent. faecalis. Interestingly, slopes of the $\ln -\log$ regression lines fall within a rather narrow range of $0.42(P$. aeruginosa) to $0.60(S$. epidermidis). The presence of magnetic deposition was detected even at lower concentrations than $10^{4}$ or $10^{3}$ c.f.u. $\mathrm{ml}^{-1}$; however, the intensity of the optical signal did not correlate with the cell concentration as evaluated by colony counting in this low concentration range, especially for $\boldsymbol{P}$. aeruginosa. A possible explanation of this effect is an inherent inability of the colony counting method to account for dead cells although these bind erbium (Evans, 1990) and can be detected by magnetic 


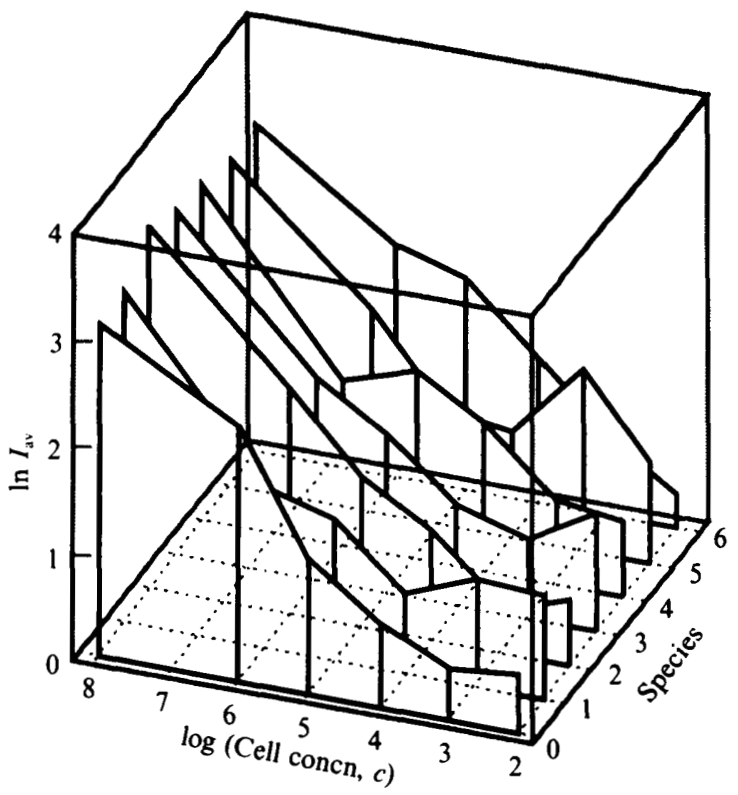

Fig. 4. Correlation of magnetic deposition density, quantified by scattered light measurement, of a single strain of bacteria, to cell concentration, $c$, in physiological saline suspensions, presented as a stack of $\ln -\log$ charts. Values on each chart represent means of repeated experiments on a single bacterial strain. Bacterial species are identified by numbers $0-6$ and are described below. For each species a regression analysis was performed in the concentration ranges in which scattered light intensity varied (almost) linearly: $\ln I_{\mathrm{av}}=m \log c+b$, as described below.

(0) E. coli

$$
m=0.58, b=-1.66,4 \leq \log c \leq 8, n=20, r=0.979
$$

(1) K. pneumoniae

$$
m=0.55, b=-1.38,4 \leq \log c \leq 8, n=20, r=0.985
$$

(2) Prot. mirabilis

$$
m=0.56, b=-1.32,3 \leq \log c \leq 8, n=25, r=0.979
$$

(3) $S$. epidermidis

$$
m=0.60, b=-1.44,3 \leq \log c \leq 8, n=25, r=0.947
$$

(4) $S$. saprophyticus

$$
m=0.51, b=-0.99,3 \leq \log c \leq 8, n=25, r=0.986
$$

(5) $P$. aeruginosa

$$
m=0.42, b=-0.48,3 \leq \log c \leq 8, n=25, r=0.935
$$

(6) Ent. faecalis

$$
m=0.45, b=-0.48,3 \leq \log c \leq 8, n=25, r=0.988
$$

separation at low c.f.u. $\mathrm{ml}^{-1}$. Moreover, cellular debris and cell culture substrate fragments could also bind erbium and concentrate on the microscope slide in the magnetic field, producing a false positive signal at low cell concentration.

Additional variability in the intensity of the optical signal around its mean value is attributed to the
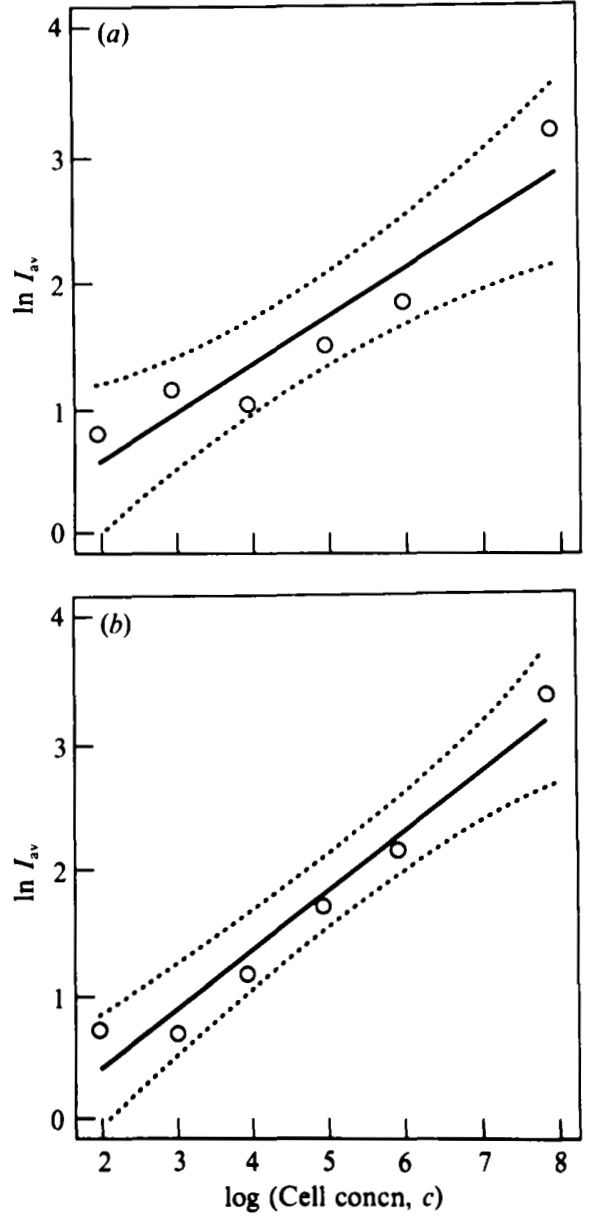

Fig. 5. Summary of results of magnetic cell deposition evaluation using scattered light measurement, as a function of cell concentration in suspension, grouped for Gram-negative ( $a$ ) and Gram-positive species (b). Solid lines represent the regression line, broken lines represent $95 \%$ confidence limits.

limitations of the light scattering technique at its present stage of development. The area viewed by the optical sensor through the $100 \times$ magnification objective covered only about one-tenth of the total width of the sample pathway and therefore was subject to interferences from random cell aggregations. This drawback of the deposition scanning could be overcome in future studies by matching the flow channel width with the light sensor viewing area diameter.

Extrapolation of the regression line to the level of $\ln$ $I_{a v}=0$, representing signal noise, intersects the abscissa at cell concentrations of about $10^{2}$ c.f.u. $\mathrm{ml}^{-1}$ for all of the bacterial species evaluated, which represents the lowest cell concentration detectable by this method in the ideal situation of absence of interference from cellular debris and non-viable cells.

Comparison of summary data for Gram-positive and 
-negative organisms is given in Fig. 5. At concentrations of $10^{4}$ c.f.u. $\mathrm{ml}^{-1}$ and higher, Gram-positive organisms apparently showed a higher scattered light signal than Gram-negative organisms; however, this observation could not be supported statistically due to high variability of the optical signal.

\section{Discussion}

Use of a paramagnetic lanthanide salt, $\mathrm{ErCl}_{3}$ at $5 \mathrm{~mm}$ concentration in $0.9 \%$ saline, allowed us to magnetically tag bacterial cells and isolate them from a flowing solution in a flow chamber exposed to a high-gradient magnetic field. The effect of magnetic interaction was observed for both Gram-positive and -negative organisms. A correlation better than 0.98 between the initial cell concentration in suspension and the cellular mass in the magnetically separated material, as measured by scattered visible light densitometry, was observed for cell concentration ranges from $10^{4}$ (for some species $10^{3}$ ) to $10^{8}$ c.f.u. $\mathrm{ml}^{-1}$, except for one species, $P$. aeruginosa. No explanation of the exceptional behaviour of $P$. aeruginosa can be given at this time; possibly, it was related to the limitations of the light scattering technique employed. Magnetic separation effects, not correlated to the cell concentration, were observed at $10^{2}$ and $10^{3}$ c.f.u. $\mathrm{ml}^{-1}$.

Erbium in aqueous solutions in the $\mathrm{pH}$ range tolerated

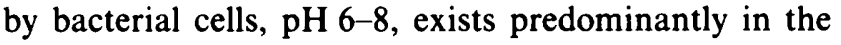
form of a trivalent cation (Evans, 1990). The mechanism of $\mathrm{Er}^{3+}$ binding to the cell surface is mostly ionic, with many different $\mathrm{Er}^{3+}$ binding sites, such as carboxyl groups of glycoproteins, differing in affinity and binding capacity (the biochemistry of lanthanides is extensively reviewed in Evans, 1990). The other well recognized lanthanide binding sites are the $\mathrm{Ca}^{2+}$ receptor sites on the cell wall (Lansman, 1990). Published observations which are typical of the cell surface binding mechanism of lanthanides include uptake of ${ }^{140} \mathrm{La}^{3+}$ by Ent. faecalis independent of temperature, accumulation of ${ }^{144} \mathrm{Ce}$ in about equal amount in live and dead cells, and the high reaction rate (equilibrium is attained in $1 \mathrm{~min}$ ) (Evans, 1990).

Erbium has a strong complexing character and thus interacts strongly with the most commonly used buffers containing phosphate or bicarbonate. Adequate results have been reported with the use of HEPES (Graham \& Selvin, 1982), and with Krebs' and Ringer's solutions in which phosphate buffer had been replaced by Tris buffer. Erbium generally has a lower reaction rate constant than $\mathrm{Ca}^{2+}$ or $\mathrm{Mg}^{2+}$ and other metal ions in binding to the external cell surface, and therefore the presence of other metal ions in solution interferes little with the $\mathrm{Er}^{3+}$ reaction with bacterial cells (Evans, 1990).
The observed increase in the magnetic deposition with increasing $\mathrm{pH}$ in the range $\mathrm{pH} 6.0$ to 10.00 , at a constant cell concentration, could be explained on the grounds of the ionic binding of $\mathrm{Er}^{3+}$ to carboxyl groups on the cell membrane surface. These groups contribute to the isoelectric point of about 6 (pI 5.32 with other functional groups blocked) (Sherbet \& Lakshmi, 1973). Other studies of the effect of extracellular $\mathrm{pH}$ on metal ion binding to bacterial cells also show increased metal ion binding with increased $\mathrm{pH}$ (Hoyle \& Beveridge, 1983). The contribution of the $\mathrm{Ca}^{2+}$ binding sites to the overall $\mathrm{Er}^{3+}$ binding was not evaluated in this study. A considerable variability in the optical signal precluded demonstrating a significant difference in the magnetic deposition between the Gram-positive and -negative bacteria treated with $\mathrm{ErCl}_{3}$ although higher binding of several metals to Gram-positive bacteria has been reported (Mullen et al., 1989).

The use of a physically dissolved ionic paramagnetic marker, such as $\mathrm{Er}^{3+}$, in this study, instead of a suspension of magnetic microbeads avoided interference from a free magnetic probe with the magnetically separated cells. Indeed, in the control samples in this study, in which only $5 \mathrm{~mm}-\mathrm{ErCl}_{3}$ solution in $0.9 \%$ saline was processed in the magnetic separator, no deposition was observed which could be directly related to the presence of $\mathrm{ErCl}_{3}$ itself. In other words, the magnetic field did not perceptibly precipitate $\mathrm{ErCl}_{3}$ from the solution unless $\mathrm{Er}^{3+}$ had been bound to the particulate elements of the suspension.

The novel magnetic separation apparatus we have described is rather simple in operation. Assuming that it could be adapted to the specialized requirements of a particular specimen, such as urine, one may hope to obtain a quantitative response of the instrument to bacteria in a specimen in about $15 \mathrm{~min}$. The magnetically induced deposition of dry cellular mass on the glass slide is suitable for storage and further analysis, such as staining for specific pathogen identification and microscopic examination. Studies on urine specimens are needed to evaluate possible interferences from other urine components such as inorganic phosphate and proteins (Pezzlo, 1988).

Helpful discussions with Dr Katherine Merritt, Case Western Reserve University, Cleveland, Ohio, USA, on bacterial properties in relation to interaction with metals, are gratefully acknowledged. This work was supported by an Edison Biotechnology Center Grant and, in part, by The Cleveland Clinic Foundation, Cleveland, Ohio, USA.

\section{References}

AHLBERG, D. H. \& W Alley, D. (1982). A new sample pretreatment for increasing the effectiveness of the Ferrograph in capturing elastomer wear debris. Basic Fluid Power Research Journal 16, 245-250. 
ANDERson, D. P. (1983). Developments in analytical ferrography. Wear 90, 187-197.

Bozorth, R. M. (1968). Ferromagnetism. Princeton, NJ: D. van Nostrand Co., Inc.

Evans, C. H. (1983). Application of ferrography to the study of wear and arthritis in human joints. Wear 90, 281-292.

Evans, C. H., \& TEW, W. P. (1983). Isolation of biological materials by use of erbium(III)-induced magnetic susceptibilities. Science 213, 653-654.

Evans, C. H. (1990). Biochemistry of the Lanthanides. New York: Plenum Press.

Graham, M. D. \& Selvin, P. R. (1982). Separation of lanthanide binding cells. Transactions of the Institute of Electrical and Electronic Engineers 18 (Magnetics), 1523-1525.

HOYLE, B. D. \& BEVERIDGE, T. J. (1983). Binding of metallic ions to the outer membrane of Escherichia coli. Applied and Environmental Microbiology 46, 749-752.

Kemshead, J. T., Elsom, G. \& Patel, K. (1990). Immunomagnetic manipulation of bone marrow and tumor cells: an update. In Bone Marrow Purging and Processing, pp. 235-252. Edited by S. Gross, A. P. Gee \& D. A. Worthington-White. New York: Wiley-Liss.
LANSman, J. B. (1990). Blockade of current through single calcium channels by trivalent lanthanide cations. Journal of General Physiology 95, 679-696.

Mullen, M. D., Wolf, D. C., Ferris, F. G., Beveridge, T. J., Flemming, C. A. \& Bailey, G. W. (1989). Bacterial sorption of heavy metals. Applied and Environmental Microbiology 55, 31433149.

Pezzlo, M. (1988). Detection of urinary tract infections by rapid methods. Clinical Microbiology Reviews 1, 268-280.

Russell, A. P., Westcott, V. C., Demaria, A. \& Johns, M. (1983). The concentration and separation of bacteria and cells by ferrography. Wear 90, 159-165.

Russell, A., Evans, C. H. \& Westcott, V. C. (1987). Measurement of the susceptibility of paramagnetically labelled cells with paramagnetic solutions. Analytical Biochemistry 164, 181-189.

Sherbet, G. V. \& LAKShMI, M. S. (1973). Characterization of Escherichia coli cell surface by isoelectric equilibrium focusing. Biochimica et Biophysica Acta 298, 50-58.

Zborowski, M., Malchesky, P. S., Savon, S. R. Green, R., Hall, G. S. \& Nosé, Y. (1991). Modification of ferrography method for analysis of lymphocytes and bacteria. Wear 142, 135-149. 